Penglin Ma Bin Du

\section{Critical care research in mainland China: more needed on the international stage}

Received: 17 January 2013

Accepted: 23 January 2013

Published online: 22 February 2013

(C) Springer-Verlag Berlin Heidelberg and ESICM 2013

Penglin Ma and Bin Du contributed equally to the article.

On behalf of the China Critical Care Clinical Trial Group (CCCCTG)

\section{P. Ma}

Department of Emergency and Critical Care Medicine, The 309 Hospital of Chinese People's Liberation Army, 17A, Hei Shan Hu Road, Beijing 100091, China

\section{B. Du (『)}

Medical ICU, Peking Union Medical College Hospital,

1 Shuai Fu Yuan, Beijing 100730, China

e-mail: Dubin98@gmail.com

The world has witnessed rapid economic progress in mainland China since it adopted the "reform and opening up" policy in 1978. The gross domestic product of China significantly increased from 268.3 billion USD in 1978 to 5.88 trillion USD in 2010. In the meantime, critical care medicine has been increasingly recognized and provided in mainland China (Fig. 1) as described in detail elsewhere [1].

It is estimated that intensive care unit (ICU) beds might account for $1.8 \%$ of total hospital beds in China [1]. Limited data also suggest that patients in Chinese ICUs exhibit a case mix similar to those in western countries. Furthermore, clinical practice in Chinese ICUs is also similar to that in developed countries [2].

However, critical care research in mainland China is still in its infancy. Several factors may explain this. First, and possibly most important, the lack of training in clinical research greatly hampers the vision of many intensivists in future academic development. Second, inadequate resources (such as the unavailability of statisticians and research nurses) often mean that intensivists have to design the study, collect data, and perform statistical analysis without external assistance. Third, lack of language proficiency may be another major obstacle for publication in peer-reviewed journals. As a result, critical care studies from China have not been published in international journals until recently. We performed a literature search in MEDLINE on 8 January 2013 to identify publications from mainland China in seven major critical care journals since 2001. A total of 218 publications were identified. The number of publications steadily increased from only 2 in 2001 to 51 in 2012 (Fig. 2). This was quite a small number considering the large population and $>50,000$ ICU beds in mainland China. Even in 2011, when the number of publications was 60, the highest during the 12-year period, it was equivalent to only $1.7 \%$ of all publications in the above journals. Most publications were original papers, including $97(44 \%)$ clinical studies, $86(39 \%)$ laboratory investigations, and $13(6 \%)$ systematic reviews/meta-analyses. There were also $4(2 \%)$ editorials/comments, $4(2 \%)$ reviews, and $13(6 \%)$ others. Of the 196 original papers, the most common areas of research were trauma (29\%), sepsis $(10 \%)$, acute lung injury $(9 \%)$, cardiovascular disease $(7 \%)$, and burns $(6 \%)$. However, despite the rapid increase in the number of publications, papers from mainland China in critical care journals had lower average impact factors and a lower average number of citations [3].

The potential for future critical care research in mainland China might be demonstrated in part by the search results in the clinical trial registry website. Up to 8 January 2013, there were 1,945 clinical trials performed in ICUs that were registered in ClinicalTrials.gov, of which $62(3.1 \%)$ were from mainland China. The number of registered studies was only 1 in 2006 and increased to 23 in 2012. Among these studies, $18(29 \%)$ were completed, $30(48 \%)$ were still recruiting participants, and 4 had not yet started. All these data suggest that there is an urgent need for high-quality studies, especially in clinical research, in China. 


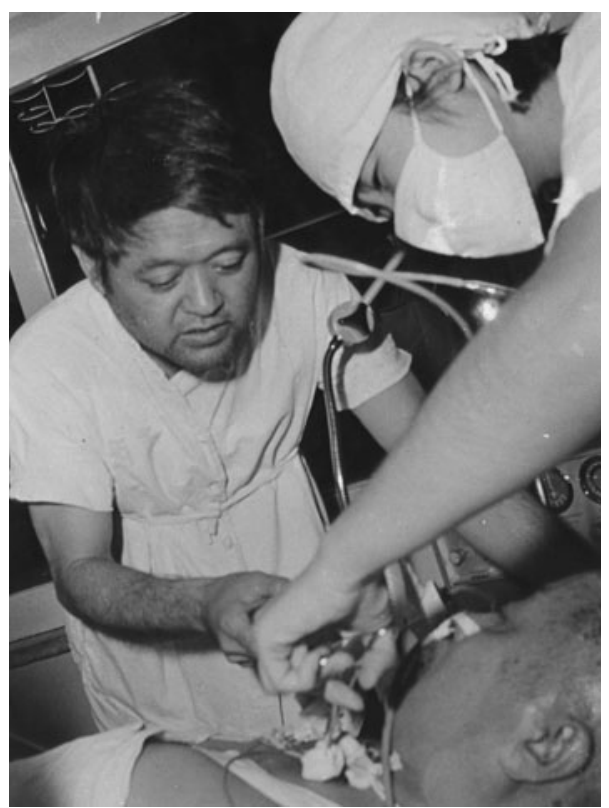

Fig. 1 Dr. Dechang Chen, the founding father of critical care medicine in mainland China, working in the surgical intensive care unit (ICU) of Peking Union Medical College Hospital, the first ICU in China

Multiple resolutions may help improve critical care research in China. In recent years, Chinese intensivists have begun to play an active role participating in international studies [1, 4-10]. Two ICUs from China participated the BEST-KIDNEY study in 2000, enrolling 77 patients or $4.4 \%$ of the cohort [5]. Seven years later, 503 patients in 57 ICUs in China were enrolled in the SAFE-TRIPS study, accounting for $25.7 \%$ of patients and $14.6 \%$ of participating ICUs [7]. It is important to understand that Chinese intensivists not only contribute patient data to these studies, but also gain experience in clinical study and, more importantly, better understanding of the standard of good clinical practice. It is also crucial to set up a platform for collaborative research in critical care. For example, the China Critical Care Clinical Trial Group (CCCCTG) was created in 2009 [1], representing the effort of Chinese intensivists to set a standard in China for the participation in large, collaborative epidemiological and clinical trials [4]. We believe that such collaboration should not only exist among ICUs, but should also expand to critical care and other specialties, even between China and other countries. Finally, the National Natural Science Foundation of China (NSFC) began to accept grant applications for critical care research in 2010. In 2012, the NSFC granted about 47 million USD to 447 medical research projects, $20 \%$ of which were considered related to critical care [11].

As a new editor, one of the responsibilities is to encourage Chinese intensivists to submit their highquality studies to Intensive Care Medicine. There are fairly good reasons to consider submission to this journal. First, Intensive Care Medicine is ranked no. 3 among 20 critical care journals, with the impact factor increasing from 4.996 in 2010 to 5.399 in 2011. Second, compared with other critical care journals, Intensive Care Medicine publishes papers in a more balanced pattern. For example, the papers published in Intensive Care Medicine in 2012 are evenly distributed among clinical trials, laboratory investigations, pediatric studies, and meta-analyses (Fig. 2). There are also papers concerning ethical and technical issues. Therefore, we believe that Intensive Care Medicine is the right choice for those who are involved in intensive care, physicians, anaesthetists, surgeons, pediatricians, as well as those concerned with pre-clinical subjects and the medical sciences basic to these disciplines. One practical way to encourage more submissions from China is to invite our European colleagues or ESICM officers to our national conference, as happened
Fig. 2 Publications of critical care research in mainland China by year in seven major critical care journals (American Journal of Respiratory and Critical Care Medicine, Chest, Critical Care, Critical Care Medicine, Intensive Care Medicine, Journal of Critical Care, Journal of Trauma)

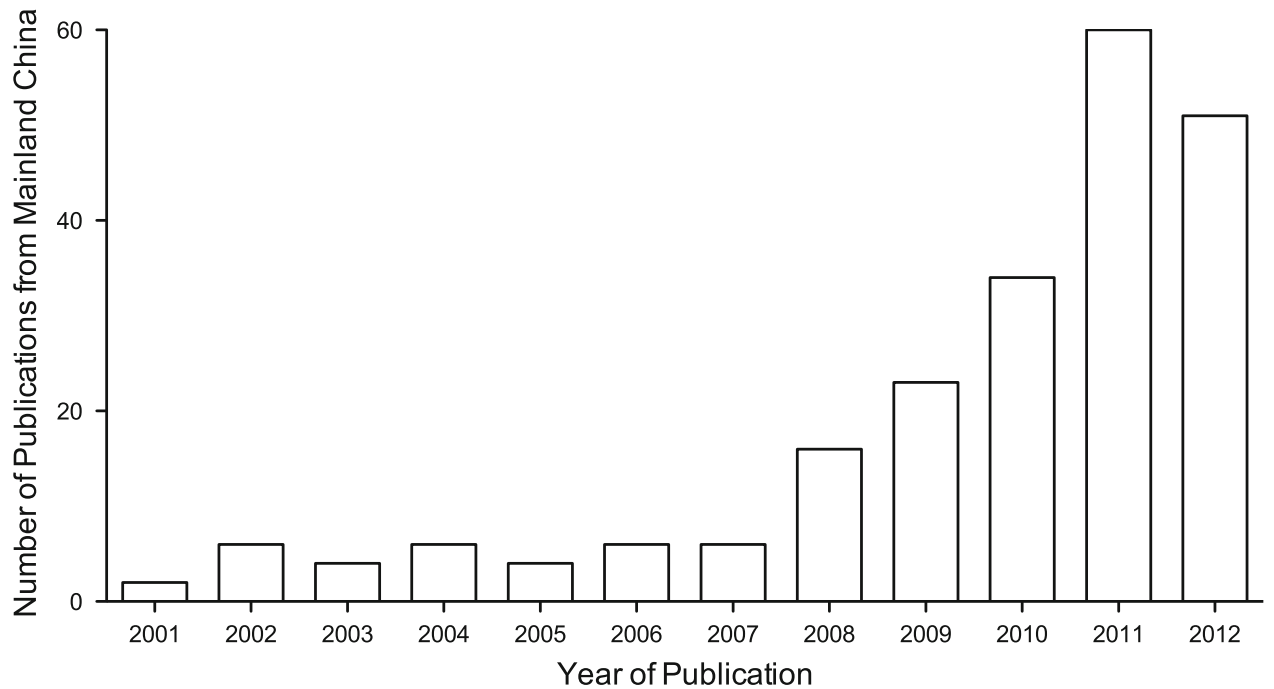


with Critical Care and the Journal of Critical Care, in order to help both sides get to know more about each other. Another solution may be to organize seminars on knowledge and clinical research skills through Springer, as some of the publishers have already done.
Conflicts of interest The authors declare that they have no conflict of interest.

\section{References}

1. Du B, Xi X, Chen D (2010) China Critical Care Clinical Trial Group (CCCCTG). Clinical review: Critical care medicine in mainland China. Crit Care 14:206

2. Du B, An Y, Kang Y (2013) For the China Critical Care Clinical Trial Group. Characteristics of critically ill patients in ICUs in mainland China. Crit Care Med 41:84-92

3. Li Z, Liao Z, Wu F et al (2010) Scientific publications in critical care medicine journals from Chinese authors: a 10-year survey of the literature. J Trauma 69:E20-E23

4. Villar J, Kacmarek RM (2013) Modern critical care medicine from China: an ancient civilization. Crit Care Med 41:343-345
5. Uchino S, Kellum JA, Bellomo R et al (2005) Acute renal failure in critically ill patients: a multinational, multicenter study. JAMA 294:813-818

6. Vincent JL, Rello J, Marshall J et al (2009) International study of the prevalence and outcomes of infection in intensive care units. JAMA 302:2323-2329

7. Finfer S, Liu B, Taylor C (2010) For the SAFE TRIPS investigators.

Resuscitation fluid use in critically ill adults: an international cross-sectional study in 391 intensive care units. Crit Care 14:R185

8. Kutsogiannis J, Alberda C, Gramlich L et al (2011) Early use of supplemental parenteral nutrition in critically ill patients: results of an international multicenter observational study. Crit Care Med 39:2691-2699
9. Phua J, Koh Y, Du B et al (2011) For the MOSAICS study group. management of severe sepsis in patients admitted to Asian intensive care units: prospective cohort study. BMJ 342:d3245

10. Tabah A, Koulenti D, Laupland K et al (2012) Characteristics and determinants of outcome of hospital-acquired bloodstream infections in intensive care units: the EUROBACT international cohort study. Intensive Care Med 38:1930-1945

11. Anonymous. Summary Report, 2012, Projects Sponsored by National Natural Science Foundation of China. Available at: http://www.nsfc.gov.cn/nsfc/cen/ xmtj/pdf/2012_table.pdf. Accessed January 8, 2013 